\title{
Sudden death after central venous cannulation
}

toute sécurité par un retour sanguin veineux et l'électrocardiographie auriculaire droite de même que par radiologie, alors quil est dangereux de provoquer des arrythmies. Pour éviter un pénétration exagérée, le guide métallique et le cathéter veineux devraient porter des graduations.

Many complications have been described following the insertion of central venous catheters ${ }^{1,2}$ but, in general, relate to local difficulty at the site of insertion, e.g., haematoma formation, or distant complications, e.g., erosion through the right atrium or superior vena cava.

Serious cardiac complications are rare. A common cardiac complication during insertion of the catheter is the occurrence of short-lived unifocal ventricular arrhythmias which are often seen in patients who are hypoxic and acidotic. $^{3}$ The diagnosis of more serious complications such as cardiac perforation or intramural thrombus formation is often delayed after insertion for 24 to $48 \mathrm{hr}$, and they are frequently only recognized at post mortem. ${ }^{4}$ It has been recommended that to minimize late complications the catheter tip be located in the lower superior vena cava. ${ }^{5}$

This paper reports a cardiac complication associated with insertion of a central venous catheter which occurred at the time of insertion and has not been previously described.

\section{Case report}

A previously fit and healthy 39 -yr-old man presented with a two-day history of severe nausea and vomiting. Before admission he had complained of increasing breathlessness.

On admission he appeared dehydrated with poor peripheral perfusion and an axillary temperature of $34^{\circ} \mathrm{C}$. Blood pressure was $80 / 40 \mathrm{mmHg}$. There was a pansystolic murmur, loudest at the apex and radiating to the left sternal edge, which had not been noted previously by the patient's family doctor. He had Kussmaul's type respiration. There was a marked pectus excavatum. An erythematous macular rash extended from the patient's upper abdomen to both groins. Abdominal examination was otherwise unremarkable. 
Initial investigations revealed $\mathrm{Hb} 15.2 \mathrm{~g} \cdot \mathrm{dl}^{-1}, \mathrm{WBC}$ 26.4. $10^{9} \cdot \mathrm{L}^{-1}, \mathrm{Na}^{+} 152 \mathrm{mmol} \cdot \mathrm{L}^{-1}, \mathrm{~K}^{+} 4.6 \mathrm{mmol} \cdot \mathrm{L}^{-1}$, and urea $24.2 \mathrm{mmol} \cdot \mathrm{L}^{-1}$. Arterial blood gas analysis whilst breathing $6 \mathrm{~L} \cdot \mathrm{min}^{-1}$ oxygen via a Hudson mask showed a metabolic acidosis with a pH 7.09, $\mathrm{PaCO}_{2}$ $2.02 \mathrm{kPa}(15.5 \mathrm{mmHg}), \mathrm{PaO}_{2} 27.5 \mathrm{kPa}(206 \mathrm{mmHg})$, BC $4.7 \mathrm{mmol} \cdot \mathrm{L}^{-1}$. Chest radiograph was normal and a 12-lead ECG showed a normal axis, sinus rhythm of $76 \mathrm{~min}^{-1}$, right bundle branch block and mild left ventricular hypertrophy.

A diagnosis of severe dehydration and metabolic acidosis possibly due to septicaemic shock was made and resuscitation was started with intravenous fluids. A decision was made to insert a central venous catheter to enable fluid replacement to be guided more accurately.

A 14 FG $(200 \mathrm{~mm})$ single lumen catheter (Hydrocath(10, Viggo-Spectramed, Swindon, UK) was prepared to be inserted into the right subclavian vein. The 450 $\mathrm{mm}$ Seldinger wire was positioned in the right subclavian vein without difficulty but partially withdrawn because of the occurrence of numerous unifocal ventricular extra systoles. The ventricular extra systoles stopped immediately after repositioning the Seldinger wire. The catheter was then rapidly inserted over the Seldinger wire, which was withdrawn. Immediately after catheter insertion the patient became unconscious, stopped breathing and had no palpable central pulse.

Cardiopulmonary resuscitation was started immediately. The three-lead ECG continued to show normal shaped complexes after the cardiac arrest despite no central pulse being palpable, which supported a diagnosis of cardiac arrest due to electromechanical dissociation. Cardiopulmonary resuscitation was started. The patient's trachea was intubated and his lungs ventilated with $100 \%$ oxygen. One litre of Ringer's lactate solution, together with four doses of adrenaline hydrochloride (total dose $8 \mathrm{mg}$ ), $3 \mathrm{mg}$ atropine sulphate, and $1 \mathrm{mg}$ anhydrous calcium chloride $(9 \mathrm{mmol})$ were given $\dot{i}$ without improvement. The patient became cyanosed despite ventilation of the lungs with $100 \%$ oxygen. It was noted that the peripheral veins in the upper body and the internal jugular veins were distended throughout the resuscitation. A tension pneumothorax was excluded by bilateral pleurocentesis but cardiac tamponade could not be excluded by subxiphoid pericardiocentesis due to the severe pectus excavatum. Resuscitation was continued for $30 \mathrm{~min}$ but was eventually abandoned.

At post mortem the striking finding was of a normal heart but with a thin-walled fibrin cyst measuring 1.5 $\mathrm{cm} \times 1.0 \mathrm{~cm} \times 0.8 \mathrm{~cm}$ arising from the tricuspid valve annulus on the atrial aspect. The cyst was filled with fluid and could easily be moved down into the right ven- tricle where it was able to prolapse into and completely obstruct the flow through the pulmonary artery outflow tract. There was no evidence of pneumothorax, cardiac tamponade or pulmonary emboli.

\section{Discussion}

The close temporal association between insertion of the central venous catheter and cardiac arrest strongly suggests a relationship between the two. Prolapse of the tricuspid valve cyst into the pulmonary artery outflow tract was well demonstrated at post mortem and could have been caused by insertion of either the Seldinger wire or the catheter. Unifocal ventricular extra systoles were seen at the time of insertion of the Seldinger wire which stopped after the wire had been withdrawn partially. The wire probably caused prolapse of the valve cyst, preventing ejection of blood from the right ventricle and causing cardiac arrest. The occurrence of electromechanical dissociation together with the clinical findings of persistent profound central cyanosis, despite adequate ventilation, and engorged peripheral veins suggests such a mechanism is likely. The chances of successful resuscitation following the cyst prolapse were low.

Unifocal ventricular arrhythmias are often seen during central venous catheterisation, are easily diagnosed at the bedside and, usually, are rapidly stopped by withdrawing the catheter or Seldinger wire.

The occurrence of cardiac arrhythmias caused by insertion of the Seldinger wire or catheter should not be used as a means of confirming correct placement. This is more safely achieved using right atrial electrocardiography ${ }^{6}$ and back flow of blood in the catheter during catheter placement, together with a chest radiograph after positioning.

To avoid excessive lengths of catheter from being introduced inadvertently most central venous catheters now have graduated markings along their length. Few Seldinger wires supplied with the catheters are similarly marked. Marking of Seldinger wires along their length might prevent accidental excessive insertion of the wire during central venous catheterisation and reduce the risk of intracardiac damage.

\section{References}

1 Morgan RNW, Morrell DF. Internal jugular catheterisation. A review of a potentially lethal hazard. Anaesthesia 1981; 36: 512-7.

2 Kaye CG, Smith $D R$. Complications of central venous cannulation (Editorial). BMJ 1988; 297: 572-3.

3 Iberti TJ, Benjamin E, Gruppi L, Raskin JM. Ventricular arrhythmias during pulmonary artery catheterization in the intensive care unit. Am J Med 1985; 78: 451-4. 
4 Ducatman BS, McMichan JC, Edwards WD. Catheterinduced lesions of the right side of the heart. $A$ one-year prospective study of 141 autopsies. JAMA 1985; 253: 791-5.

5 Food and Drug Administration: Precautions necessary with central venous catheters. FDA Task Force. In: FDA Drug Bulletin, July 1989, 15-6.

6 McGee WT, Ackerman BL, Rouben LR, Prasad VM, Bandi $V$, Mallory $D L$. Accurate placement of central venous catheters: a prospective, randomized, multicenter trial. Crit Care Med 1993; 21: 1118-23. 